\title{
Physical, chemical and biological behaviour of radioactive chlorine and jodine in soils
}

\author{
A. Bostock, D. Ashworth and G. Shaw \\ Department of Environmental Science \& Technology, Imperial College at Silwood Park, \\ Ascot SLS TPY, U.K.
}

\begin{abstract}
A series of laboratory-based soil column studies has been carried oul to detemine the comparative behaviour of the radioactive halogens ${ }^{36} \mathrm{Cl}$ and ${ }^{125} \mathrm{I}$ (as a surrogate for ${ }^{129} \mathrm{I}$ ) in the soil-ptant system. Physical migration of ${ }^{36} \mathrm{Cl}$ in the soil appcars to be unretarded due to its presence predominaritly in the chloride form. This lead to substantial accumulation of ${ }^{36} \mathrm{Cl}$ at the soil surface in a column experiment in which the net flux of water was upwards. Physical migration of ${ }^{125} 1$ in soils appears to be relatively rapid at low oxidation-reduction potentials, but is substantially retarded under more oxic soil conditions. This lead to accumulation of ${ }^{125} I$ in the zone of transition between anoxic and oxic zones in the soil. Gel filtration chromatography confirmed that the predominant chemical form of ${ }^{36} \mathrm{Cl}$ in the soil is the chloride anion. Conversely, ${ }^{125}$ I showed a strong tendency to associate with both high and low molecular weight fractions of soil humic substances, though its attachment to the low molecular weight fraction appears to be more specific than to the high molecular weight fraction. Soil-plant transfer was measured for both ${ }^{36} \mathrm{Cl}$ and ${ }^{125} \mathrm{I}$ in rye grass swards in undisturted soil columns. Biological assimilation of ${ }^{36} \mathrm{Cl}$ was particularly significant, with more than $50 \%$ of the total ${ }^{36} \mathrm{Cl}$ activity in the soil being taken up by the grass sward after three weeks' growth. Uptake of ${ }^{125} 1$ by grass swards was less spectacular, though still resulted in approximately $1 \%$ of the total soil ${ }^{125}$ I activity being assimilated even though the standing biomass of the grass sward was low.
\end{abstract}

\section{INTRODUCTION}

The potential for the disposal of radioactive wastes in geological repositories presents a new challenge for radioecology. The timescale over which leakage from repositories and eventual emergence into the biosphere of radionuclides is likely to occur is so long $(>1000 \mathrm{y})$ that only long-lived radionuclides have the potential to become significant environmental contaminants from this source. Furthermore, only those radionuclides with considerable mobility within the geosphere will emerge into the surface environment in significant quantities. The radioactive halogens ${ }^{36} \mathrm{Cl}$ and ${ }^{129} 1$ (300 thousand and 15.7 million year half lives, respectively) both possess a combination of long physical half life and a high degree of geospheric mobility, which dictates that their potential environmental impact as a result of radioactive waste disposal should be investigated thoroughly. We have conducted a series of experiments to determine the physical, chemical and biological behaviour of ${ }^{36} \mathrm{Cl}$ and ${ }^{125} \mathrm{I}$ (as a surrogate for ${ }^{129} \mathrm{I}$ ) in both undisturbed and repacked soil columns. The aim of this paper is to summarise some of the most important results from these experiments and to compare and contrast the behaviour of radioactive chlorine and iodine in the soil-plant system.

\section{MATERIALS AND METHODS}

\subsection{Physical migration of ${ }^{36} \mathrm{C}$ and ${ }^{125} \mathrm{I}$ in soils}

Homogeneous soil columns were constructed by packing a screened $(1 \mathrm{~cm}$ mesh size) sandy loam into plastic tubes $50 \mathrm{~cm}$ long and $15 \mathrm{~cm}$ in diameter. Each packed column was placed in a reservoir containing water contaminated with either ${ }^{36} \mathrm{C} /$ or ${ }^{125} \mathrm{I}$ at a target activity concentration of $20 \mathrm{kBq} \mathrm{L}{ }^{-1}$ (the initial chemical form was either chloride or iodide, respectively). This allowed the establishment of a water table at a height of $5 \mathrm{~cm}$ from the base of the column, ie. at a depth of $45 \mathrm{~cm}$ from the soil surface. No additions of water were made to the soil surface. Consequently, when rye grass (Lolium perenne cv. 
Profit) was uniformly planted at the column surface the only source of water for plant growth was from the saturated and increasingly anoxic lower portions of the column. The evapotranspirational pull exerted by the rye grass resulted in a net flux of water towards the column surface, thus providing a driving force for the migration of ${ }^{36} \mathrm{Cl}$ and ${ }^{125} \mathrm{I}$ toward the soil surface. A string of platinum electrodes was implanted at various depths in the columns to measure oxidation-reduction potential in the soil throughout the experiment. At periods of 3 months, up to a total of 12 months, selected columns were destructively sampled by splitting and cutting the soil into $2 \mathrm{~cm}$ or $5 \mathrm{~cm}$ layers. These were analysed for total ${ }^{36} \mathrm{Cl}$ activity by extraction with deionised water and liquid scintillation counting, and for total ${ }^{125} \mathrm{I}$ activity by gamma ray spectrometry of solid soil samples using an automated well-type $\mathrm{NaI}(\mathrm{Tl})$ detector.

\subsection{Chemical speciation of ${ }^{36} \mathrm{Cl}$ and ${ }^{125} \mathrm{I}$ in soils}

Selected soil samples were used to determine the degree of association of ${ }^{36} \mathrm{Cl}$ and ${ }^{125} \mathrm{I}$ with naturally occurring humic substances. The soil was first treated by shaking $4 \mathrm{~g}$ with $20 \mathrm{ml}$ of $0.5 \mathrm{M} \mathrm{NaOH}$, which is a non-specific extractant for soil organic matter. $1 \mathrm{ml}$ of this crude extract was then injected onto a $50 \mathrm{~cm}$ gel filtration chromatography (GFC) column which was packed with a gel with a nominal upper molecular weight discrimination limit of $10 \mathrm{kDa}$ (Fractogel TSK HW40). Samples were pumped down the column at a rate of approximately $1 \mathrm{ml}$ minute $e^{-1}$, and fractions of the colums eluent were collected at 2 minute intervals. Both total UV absorbance at $280 \mathrm{~nm}$ (as a measure of humic substance concentration) and total ${ }^{36} \mathrm{Cl}$ or ${ }^{125} \mathrm{I}$ activity were determined in each GFC fraction. Chromatograms were constructed by plotting UV absorbance and total radioactivity against elution time, normalised to the elution time of a completely excluded macromolecule (Dextran Blue, $\mathrm{M}_{\mathrm{r}}=2 \mathrm{MDa}$ ).

\subsection{Biological uptake of ${ }^{36} \mathrm{CI}$ and ${ }^{125} \mathrm{I}$ by a mixed grass sward}

The degree of root uptake by mixed grass swards of ${ }^{36} \mathrm{Cl}$ and ${ }^{125} \mathrm{I}$ was determined in experiments employing both re-packed soil columns and short $(20 \mathrm{~cm})$ undisturbed soil cores. The cores were obtained by driving $11 \mathrm{~cm}$ diameter plastic pipes into a forest soil (a podzol with well-developed surface organic horizons) underling mature Pinus sylvestris and a sandy loam covered with a close-grazed mixed grass sward, both situated in south east England. The cores were transferred to a controlled environment cabinet and injected at a depth of $7 \mathrm{~cm}$ with $50 \mathrm{kBq}$ of either ${ }^{36} \mathrm{Cl}$ (as chloride) or ${ }^{125} \mathrm{I}$ (as iodide). After 2 and 20 days' incubation the cores were destructively sampled and the activities of ${ }^{36} \mathrm{Cl}$ and ${ }^{125} \mathrm{I}$ in grass and soil were determined as described in section 2.1. Transfer factors (activity concentration ratios) and total inventory ratios (total $\mathrm{Bq}$ in plant tissue : total $\mathrm{Bq}$ in the soil core) were calculated using these measurements and median values and $90 \%$ confidence limits determined using a Monte Carlo sampling technique in order to take sampling uncertainties into account.

\section{RESULTS AND DISCUSSION}

\subsection{Physical migration of ${ }^{36} \mathrm{Cl}$ and ${ }^{125} \mathrm{I}$ in soils}

The results of soil migration studies are summarised for columns sampled after 3 months and 9 months in Figure 1. The physical transport of both ${ }^{36} \mathrm{Cl}$ and ${ }^{125} \mathrm{I}$ is relatively rapid when compared with other more strongly retarded radionuclides such as ${ }^{137} \mathrm{Cs}$. Chloride is commonly assumed to be a perfectly conservative tracer of soil water movement with a solid-liquid distribution coefficient $\left(\mathrm{K}_{d}\right)$ close to zero, hence the ready transport of ${ }^{36} \mathrm{C}$ l to the soil sufface in a period of less than 9 months is to be expected. Evidence of the free transport of ${ }^{36} \mathrm{Cl}$ up the experimental soil columns is given by the emerging pattem of accumulation at the soil surface in the 9 month column. This is due to the evaporation of water at the soilvegetation surface which leaves an increasing activity of ${ }^{36} \mathrm{Cl}$ at the soil surface as it proceeds.- The process of salt accumulation, or salinisation, is commonly seen in arid environments in which salt pan formation is common. 

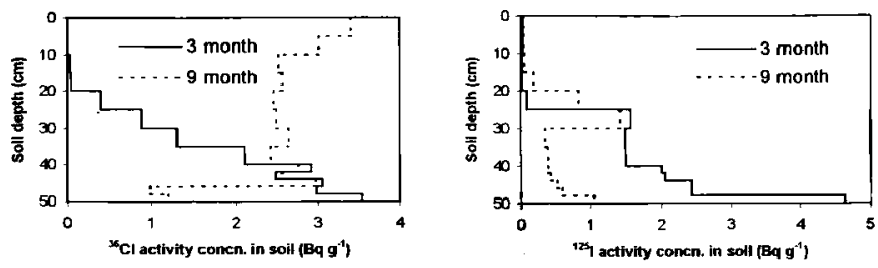

Figure 1: Vertical profiles of ${ }^{36} \mathrm{Cl}$ and ${ }^{125} \mathrm{l}$ distribution after 3 and 9 months' migration from the bottom of $50 \mathrm{~cm}$ soil columns towards the soil surface. The primary driving force for this migration is provided by evapotranspiration of water through a rye grass sward which is planted at the column surface.

The behaviour of ${ }^{125} \mathrm{I}$ is somewhat different to that of ${ }^{36} \mathrm{Cl}$. While the initial migration of ${ }^{123} \mathrm{I}$ was quite rapid over the first 3 months of the experiment, it was evident that, after 9 months, a region of ${ }^{125} \mathrm{I}$ accumulation at a soil depth of $25-30 \mathrm{~cm}$ was developing. Geometric mean $K_{d}$ values for radioactive iodine range from 1 to 5 for sandy and loamy soil, respectively [1], although the oxidation state in which iodine is present within the soil is thought to be directly dependent on both oxidation-reduction potential and $\mathrm{pH}$ [2]. This is supported by observations that iodide is the major free form of iodine found in flooded soils with low oxidation-reduction potentials $[3,4]$. Furthermore, it has also been found that when saturation is reduced (to 70 or 89 percent) and soil oxidation-reduction potential increases, the major form of iodine is found to be iodate [4]. Figure 2 shows a typical profile of oxidation-reduction potential measured in the experiemntal soil columns. The zone of ${ }^{125} 1$ accumulation in the column experiment reported here coincides with the zone of transition between the anoxic, saturated soil in the lower 10 to 15 cen of the columns and the relatively dry, oxic upper portion of the coltumn. After 9 months this zone of accumulation was exaggerated by the radioactive decay of ${ }^{125} \mathrm{I}(\mathrm{t} t / 2=60 \mathrm{~d})$ below $30 \mathrm{~cm}$ (no attempt was made to correct for radioactive decay because the target activity concentration of ${ }^{125} \mathrm{I}$ in the column reservoir solution was maintained using fresh stock solutions of ${ }^{125}$ I made up on different dates).

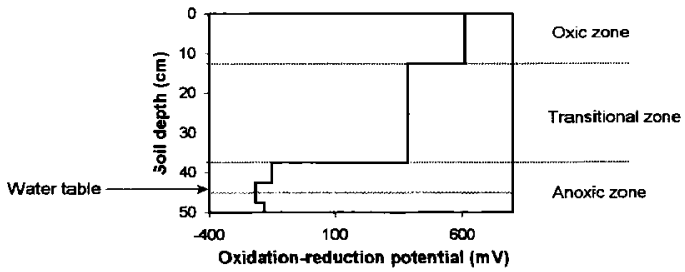

Figure 2: A typical vertical profile of oxidation-reduction potential in a $50 \mathrm{~cm}$ experimental soil column. Anoxia in the lower portion of the column is due to saturation with water in the region around the water table.

It can be concluded from these experiments that the migration of ${ }^{36} \mathrm{Cl}$ in soil is likely to be rapid, resulting from the existence of this radionuclide in the form of the chloride anion which is probably not easily 
altered under normal soil conditions. Conversely, the migration behaviour of ${ }^{125} 1$ in the soil is likely to be strongly affected by changes in oxidation-reduction potential due to natural events such as soil flooding or seasonal changes in the soil water table.

\subsection{Chemical speciation of ${ }^{36} \mathrm{Cl}$ and ${ }^{125} \mathrm{I}$ in soils}

GFC chromatograms for humic substances, ${ }^{36} \mathrm{Cl}$ and ${ }^{125} \mathrm{I}$ are shown in Figure 3. These were obtained for $0.5 \mathrm{M} \mathrm{NaOH}$ extracts of the sandy loam soil used in the soil column experiments described above. Humic substances extracted from this soil show two characteristic peaks. The first and major peak elutes within the GFC column void volume (relative elution time $=1.0$ ) indicating that it consists of a molecule, or mixture of molecules, with a molecular weight in excess of the upper molecular weight discrimination limit of the gel used (ie. $>10 \mathrm{kDa}$ ). The second and minor peak elutes at a relative elution time of approximately 2.2 to 2.4 , indicating relatively low molecular weight material (ie. $<10 \mathrm{kDa}$ ). Cooke et al. [5] have used proton nuclear magnetic resonance spectroscopy ( $\left.{ }^{1} \mathrm{H}-\mathrm{NMR}\right)$ to show that these sub-fractions differ in chemical character and molecular size. 'H-NMR resonances for the major GFC fraction indicate a large amount of macromolecular and carbohydrate-type material, while the minor fraction contains much less macromolecular material. It is evident from Figure 3 that ${ }^{125} \mathrm{I}$ has a strong tendency to associate with both major and minor humic substance peaks, although the larger ratio of ${ }^{125} \mathrm{I}$ activity : UV absorbance in the case of the minor humic peak suggests a strongly specific association between radioactive iodine and low molecular weight humic substances in soils. Conversely, ${ }^{36} \mathrm{Cl}$ appeared to show no association with either major or minor peaks of humic substances. The primary ${ }^{36} \mathrm{Cl}$ peak occurred at a relative elution volume of approximately 1.1 , at which it had previously been determined that ${ }^{36} \mathrm{Cl}$ in the chloride form eluted from the GFC column. The existence of ${ }^{36} \mathrm{Cl}^{-}$in the experimental soils is consistent with the observation of rapid and unretarded migration of ${ }^{36} \mathrm{Cl}$ in the column experiments described in section 3.1 . However, ${ }^{36} \mathrm{Cl}$ has previously been found by Lee et al. [6] to occur, at least in part, in association with the low molecular weight humic substance fraction for which ${ }^{125}$ I has an apparently high affinity. Oberg [7] has determined that, in forest soils, organic forms of chlorine can be quantitatively significant, though the conditions under which ${ }^{36} \mathrm{Cr}^{-}$might be converted to a humic-associated form are still not clear.
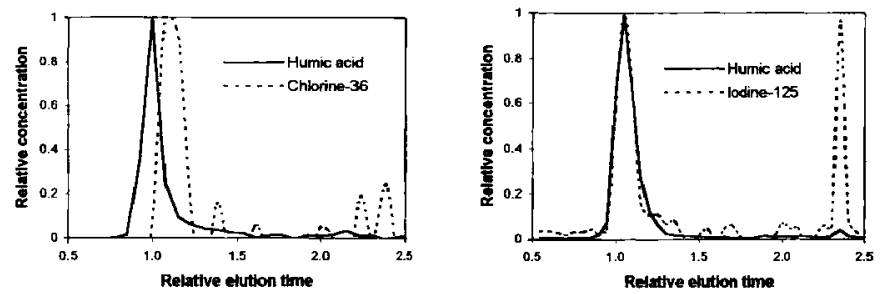

Figare 3: GFC chromatograms for 0.5 M NaOH extracts obtained from the sandy loam soil used in soil migration studies. 


\subsection{Biological uptake of ${ }^{36} \mathrm{Cl}$ and ${ }^{125} 1$ by grass swards}

Very few soil-plant transfer factors have been determined either for radioactive chlorine or iodine. This is particularly surprising in the case of iodine, but probably reflects the fact that the major interest has been in

${ }^{31}$ I release following nuclear accidents or weapons detonations. Since ${ }^{131} \mathrm{I}$ has a radioactive half life of only 8 days, direct contamination of plant leaf surfaces has been a more significant radiological exposure route in these scenarios. In the case of ${ }^{36} \mathrm{Cl}$, soil-plant transfer factors are almost absent from the literature. Sheppard et al. [8] have recently published a substantial collection of soil-plant concentration ratios for stable (non-radioactive) chloride which indicates that uptake of ${ }^{36} \mathrm{Cl}$ by plants is potentially very significant. Figure 4 shows that the root uptake of ${ }^{36} \mathrm{Cl}$ by grass swards in undisturbed soil columns was, indeed, very substantial with soil-plant transfer factors (activity concentration ratios) exceeding 100, and inventory ratios exceeding 1.0. The inventory ratio is perhaps the most indicative measure of the degree of incorporation of ${ }^{36} \mathrm{Cl}$ by grass swards: a value in excess of unity indicates that more than $50 \%$ of the total ${ }^{36} \mathrm{Cl}$ activity in the soil-plant system had been biologically assimilated, despite a relatively low standing biomass. Soil-plant transfer factors and inventory ratios for ${ }^{125} I$ were approximately 2 to 3 orders of magnitude lower than for ${ }^{36} \mathrm{Cl}$. Nevertheless, an inventory ratio of 0.01 indicates that approximately $1 \%$ of ${ }^{125}$ I was biologically assimilated by grass swards. A $1 \%$ depletion of soil iodine is significantly greater than the $0.01 \%$ depletion due to physical processes such as volatilisation which has been measured in parallel experiments [9].
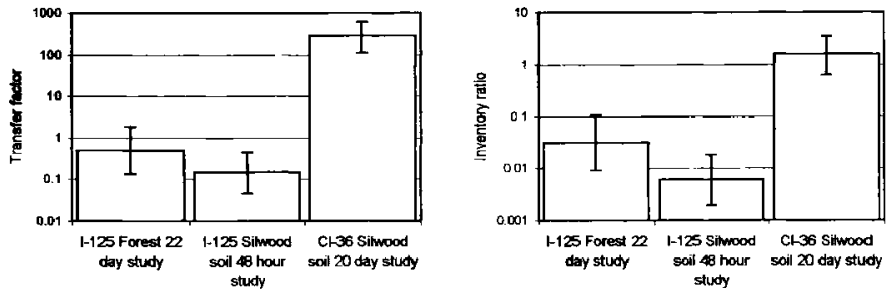

Figure 4: Soil-plant transfer factors (activity concentration ratios) and inventory ratios for ${ }^{36} \mathrm{Cl}$ and ${ }^{125} \mathrm{I}$ determined for grass swards growing on undisturbed soil columns into which each radionuclide had been injected in the chloride or iodide form, respectively.

\section{SUMMARY AND CONCLUSIONS}

Although ${ }^{36} \mathrm{Cl}$ and ${ }^{125} \mathrm{I}$ belong to the same chemical group, their behaviour in the soil-plant system is significantly different. ${ }^{36} \mathrm{Cl}$ appears to undergo unretarded physical transport in the soil in the form of the chloride (Cl) anion, which results in a very high degree of biological uptake. Conversely, ${ }^{125} \mathrm{I}$ shows a strong tendency to associate with naturally occurring hurnic substances in the soil. This binding of radioactive iodine appears to be dependent on the soil's oxidation-reduction potential and results in a much lower degree of biological uptake than is observed for ${ }^{36} \mathrm{Cl}$. Despite these differences between radioactive chlorine and iodine, biological assimilation of both ${ }^{36} \mathrm{Cl}$ and ${ }^{125} \mathrm{I}$ appears to be much more significant than for other more strongly sorbed radionuclides such as ${ }^{137} \mathrm{Cs}$. 


\section{Acknowledgments}

These studies were conducted as part of the United Kingdom Nirex Safety Assessment Research Programme. The authors are grateful to A. P. Butler, H. S. Wheater and J. N. Bell for valuable discussion.

\section{References}

[1] IAEA Handbook of parameter values for the prediction of radionuclide transfer in temperate environments. Technical Reports Series No. 364 (1994) International Atomic Energy Agency, Vienna.

[2] Yu, Z., Wamer, J.A., Dahigren, R. A. \& Casey, W. H. Reactivity of iodide in volcanic soils and noncrystalline soil constituents. Geochemica et Cosmochimica Acta, 60 (1996) 4945-4956,

[3] Gee, GW, Rai, D, Serne, R. J. Mobility of radionuclides in soil systems. SSSA Spec. Publ. 11 (1983) 203-227.

[4] Yuita, K. Dynamics of iodine, bromine and chlorine in soil : 2 Chemical forms of iodine in soil solution. Soil science and plant mutrition 38 (1992) 281-287.

[5] Cooke, C. M, Shaw, G., Lester, J. N. and Collins, C. D. Interaction of formaldehyde with soil humic substances: separation by GFC and characterisation by ${ }^{1} \mathrm{H}-\mathrm{NMR}$. Chemosphere (2001) submitted

[6] Lee, R. T., Shaw, G., Wadey, P. and Wang, $X$. Specific association of ${ }^{36} \mathbf{C l}$ with low molecular weight fractions of humic acids. Chemosphere 43 (2001) 1063-1070.

[7] Oberg, G. Chloride and organic chlorine in soil. Acta Hydrochim. Hydrobiol. 26 (1998) $137-144$.

[8] Sheppard, S. C., Evenden, W. G. and MacDonald, C. R. Variation among chlorine concentration ratios for native and agronomic plants. J. Emiron. Radioactivity 43 (I999) $65-76$.

[9] Bostock, A. Volatilisation of ${ }^{129}$ I from coniferous forest and grassland soils. MSc Thesis (2000) Imperial College of Science, Technology and Medicine, University of London. 